\title{
UNA ENTREVISTA A JORGE YÁÑEZ: EL ORIGEN DE LOS ENCUENTROS DE PAYADORES EN CHILE
}

\author{
Mario Gómez \\ Universidad Austral de Chile \\ mariogomezy@gmail.com
}

En mi trabajo de elaboración de tesis magistral en Literatura abordé el estudio de la paya chilena. Para ello, fue necesario tomar la huella de la génesis del espectáculo de la paya, vale decir, el encuentro de payadores. Así que contacté al actor, músico y payador Jorge Yáñez (1937). Este artista estuvo involucrado directamente en la organización de los primeros encuentros de payadores como los conocemos hoy, al haber sido parte de la mítica Agrupación Críspulo Gándara, fundadora de la paya como un espectáculo en 1980. Me dirigí a su casa en San Sebastián, comuna de Cartagena, Chile, un 28 de septiembre de 2018, para obtener la entrevista que doy a conocer hoy. En aquella tarde, Yáñez no solo contó la historia de los encuentros de payadores, sino que además habló de su propio acercamiento a la poesía popular y entregó su visión sobre ella, la poesía en general y el trabajo de los payadores. Por todo ello, me pareció importante relevar este testimonio, en el que aparecen personas y sucesos escasamente conocidos más allá del ámbito de los poetas populares. Mi intención es convocar a los lectores para estudiar y, sobre todo, disfrutar el arte de la poesía oral improvisada.

JoRge YÁÑEZ (J. Y.).: Siempre me gustó la poesía rimada. Y cuando ya vinieron los poetas sueltos y libres... Yo siempre he pensado que esos poetas tienen algo que decir; entonces, son una especie de escritores. Entonces dejaron la rima, y si dejaron la rima fue porque era mucho trabajo, era más fácil escribir unas líneas y darles un carácter anecdótico, filosófico o literario. Pero encerrar un pensamiento en cuatro líneas o en diez, eso ya es más difícil. Entonces, siendo actor, fundamentalmente me gustaba recitar 
poemas criollos, campesinos, populares que me gustaban. Y el primer poeta que yo conocí - popular- era el "Piojo" Salinas.

Mario Gómez (M. G.): ¿Año, más o menos?

J. Y.: Como el 70, por ahí.

M. G.: ¿Y cómo conoció al Piojo?

J. Y.: En las peñas, en las Chile ríe y canta.

M. G.: ¿Usted fue de público?

J. Y.: De público. Me gustaba, me atraía el canto popular, sobre todo el folclor, la gente que cantaba y se expresaba en versos.

M. G.: ¿Tenía noción de los payadores antes de ver al Piojo?

J. Y.: Sabía que había payadores, pero no los conocía. En la literatura sí.

M. G.: El primer payador que vio en la vida, entonces, fue el Piojo.

J. Y.: Claro. Pero el Piojo era, por así decirlo, era un bribón (ríe). El Piojo era muy ingenioso. Todas las cuartetas que inventaba llevaban una talla.

M. G.: ¿Y qué clase de humor tenía el Piojo?

J. Y.: Era muy inteligente. Improvisaba sobre cualquier cosa. Pero siempre en ese tiempo era en cuartetas.

M. G.: ¿Nadie hacía la décima?

J. Y.: Todavía no. Cuando pasaron los años, yo una vez inventé una cuarteta...

En aquel momento se me ocurrió preguntarle por el golpe de Estado. Yáñez retomó el hilo de su historia con el Piojo más adelante.

M. G.: En algún momento después del golpe, ¿tuvo que salir de Chile?

J. Y.: Nunca. Adónde me iba a ir... Tenía familia, hijos. Y el canto mío siempre fue un canto alegre, siempre fue un canto que cultivaba la manera de ser de la gente, describía sus historias en verso, yo las escribía. Siempre hice canciones, desde el colegio. Yo estudié mucho de noche. Uno de los grandes poetas que yo... fue Carlos Pezoa Véliz. Él se enfermó, lo pilló el terremoto de 1906 en Viña del Mar, trabajaba él en la municipalidad, y le atacó las piernas, estuvo mucho tiempo en el Hospital Alemán. Ese fue uno de mis poetas predilectos, después fue la Gabriela, después fue Neruda, y así fui conociendo un montón de poetas a través de la literatura.

M. G.: Y poetas populares, recién el Piojo.

J. Y.: Sí. 
M. G.: ¿Usted cree que existe una diferencia tan tajante entre literatura popular y literatura "culta"?

J. Y.: Yo creo que todo es literatura, todo. Desde el momento en que el hombre aprendió a escribir ya empezó a hacer literatura.

M. G.: Y lo que hacemos los payadores improvisando, ¿también?

J. Y.: Es parte de la literatura popular. Y además que lo que hacen los payadores es algo súper entretenido, súper ingenioso. El hecho de dominar el verso y expresar las ideas que ellos tienen en versos rimados, eso es muy antiguo. Yo creo que los grandes payadores aprendieron a payar en las iglesias cuando iban a sus fiestas religiosas, y ahí aparecen los primeros poetas que yo conocí, que después de cantar a lo divino cosas religiosas, cantaban a lo humano entre ellos. Eso yo lo descubrí en los libros.

M. G.: ¿A quién leyó?

J. Y.: El primer libro que llegó a mis manos fue de Juan Uribe. Él escribió un libro sobre cuatro payadores, yo lo tengo por ahí en mi biblioteca. Y leyendo a este caballero me gustó mucho su seriedad para afrontar el tema de los payadores, el respeto que él le tenía a los payadores. Y creo que andaba organizando él mismo encuentros.

M. G.: De hecho, él gestionó el primer congreso de poetas populares el año 1954 en la Universidad de Chile.

J. Y.: Ese libro también lo tenía yo. Sí, me acuerdo mucho de ese congreso. Pero, como te digo, lo tomaba como lectura. Entonces, cuando lo conocí en Chile ríe y canta yo iba a recitar a esos lugares, recitaba al mismo Carlos Pezoa Véliz, a Carlos Padilla, a Víctor Domingo Silva, a Joaquín Fabres Ahumada, de repente a Neruda... Pero de payar no tenía idea. Entonces, cuando yo veía al Piojo cómo payaba frente al público improvisando lo encontré sumamente ingenioso.

M. G.: ¿Y qué hacía el Piojo? ¿Pies forzados, pregunta y respuesta?

J. Y.: Nada. Improvisaba no más en cuarteta.

M. G.: ¿Pero pedía temas al público?

J. Y.: Nada, nada. Él era un payador, no tenía nada que ver con el espectáculo de la paya. Recuerdo que en una oportunidad yo escribí una cuarteta porque él siempre le echaba tallas al público. Entonces, le escribí una cuarteta para responderle si alguna vez me tocaba. Y me tocó. Me echó una talla y yo, que le había escrito una cuarteta, le respondí. Eso fue una audacia de mi parte, porque al responderle me respondió con otra cuarteta, y otra, y otra (risas) y yo quedé ahí no más. Y ahí nos hicimos amigos con el Piojo. Además, teníamos 
una vida en común. Éramos los dos obreros, habíamos sido trabajadores, nos habíamos criado en los antiguos centros del SENAME. Existía el Consejo de Defensa del Niño. Y el Consejo de Defensa del Niño tenía hogares en todo Santiago. Yo me crie en uno de esos, y conversando con el Piojo también se crio en uno de esos, así que nos hicimos muy amigos debido a la experiencia popular que teníamos. Entonces, yo me empecé a ejercitar escuchando al Piojo Salinas y aprendí a payar con él en cuartetas, ya nos hicimos más amigos todavía porque hacíamos contrapuntos.

M. G.: ¿Y la rima era consonante o era asonante?

J. Y.: Consonante, siempre consonante. Entonces cuando pasan los años, voy descubriendo yo, sigo leyendo, y no había encuentros de payadores en ese tiempo. Puede que el Piojo se trenzara con algún otro, pero era algo ocasional, repentino, igual que la paya. Y como a mí me gustaba siempre la poesía popular, aprendí a payar con él. Y al tener ese contacto después conocimos a Santos Rubio. Ellos eran más amigos que yo, y conocí al Santos Rubio, al Alfonso, al Popeta, al Pedro Yáñez, y a otros viejos. Y me gustaba eso. Y cuando el año 80 este grupo de payadores decide organizarse y aprender a payar bien además de las cuartetas, en décimas.

M. G.: ¿Y cómo se les ocurrió?

J. Y.: Yo creo que se le ocurrió al Pedro y al Santos Rubio. Ellos [lo] cultivaban porque tienen un historial campesino. Yo nunca he sido campesino; me gusta sí la cultura del campo, me gusta la gente del campo, conversar con ellos, conocer su paisaje, sus costumbres, su vida, es gente muy noble los poetas populares y los payadores. Y así me fui metiendo en este mundo. Y cuando se creó la Críspulo Gándara, que se le puso [el nombre] por el famoso duelo de payadores que era el referente más antiguo que teníamos ${ }^{1}$. Y Críspulo Gándara existió; yo no sabía eso, para mí fue una felicidad conocerlo alguna vez en un encuentro de payadores. Pero tenía una particularidad muy especial: payaba de a dos cuartetas, no hacía décimas. Y otro señor que también fue muy conocido - pero a través de la literatura y después lo conocí personalmente- fue Lázaro Salgado, que fue el maestro del "Bigote" Villalobos. Bigote Villalobos fue siempre muy amigo de Lázaro Salgado. Un día yo lo encuentro al Lázaro Salgado en la calle payando y cantando con su señora, y yo que ya sabía payar le contesté en la calle.

J. Y.: ¿Con una cuarteta?

Se refiere a un certamen de payadores que hubo en 1965 en Concepción. 
M. G.: Claro. Después él inventó otra y yo le respondí otra porque ya sabía, pero yo tratando de acercarme a Lázaro Salgado para decirle que lo admiraba, que realmente era un referente para los poetas populares y para los payadores. Pero el viejo era único, era él no más. Le encantaba hacer décimas, pero era poco amistoso. Había que conocerlo más íntimamente, y el Bigote fue uno de esos; creo que vivían en el mismo barrio. Y eso fue lo que yo conocí de Lázaro Salgado, nada más que eso. Pero en la Críspulo Gándara aprendimos entre todos, se nos enseñó la décima Santos Rubio, Pedro Yáñez, el Alfonso, el Popeta. El Popeta era un campesino campesino, dirigente campesino. Y él organizó encuentros de payadores en Melipilla; allá tuvimos los primeros encuentros nosotros antes de la Críspulo Gándara, íbamos todos los que después conformamos la Críspulo Gándara.

M. G.: ¿Y cuándo partieron esos encuentros en Melipilla? Porque la Críspulo fue del 80.

J. Y.: Antes se hacían los encuentros en Melipilla, que no era mucho, pero lo organizaba este caballero, el Popeta. Y ahí nos conocimos porque fuimos a varios encuentros y decidimos, entonces, aprender a payar de la mejor manera que pudiéramos.

M. G.: ¿Y qué es lo que ocurría en esos encuentros en Melipilla? ¿Cómo era la dinámica, el espectáculo que se veía?

J. Y.: Cada uno payaba con otro, y eso era todo. Se subía, suponte tú, el Pedro con el Santos.

M. G.: ¿Y hacian un contrapunto en cuartetas?

J. Y.: Claro. Después yo subía con el Piojo también, y los otros poetas. Pero al darnos cuenta de que la paya seguía avanzando, estos viejos queridos -Santos Rubio y el Pedro especialmente, y el Popeta-nos hicieron conocer la décima, que podíamos payar en décima. Yo me resistí mucho tiempo porque estaba acostumbrado a payar en cuarteta, me costaba mucho hacer décimas, hasta el día de hoy me cuesta. Pero eso fue muy bueno, lo de la Críspulo Gándara. Entonces, hacíamos un programa, por así decirlo. Teníamos que darle una puesta en escena que tuviera un inicio, un desarrollo y un desenlace, igual que en el teatro. Entonces, yo hacía mi aporte en ese sentido.

M. G. ¿Por qué surge esta necesidad de esta puesta en escena de la paya?

J. Y.: Porque éramos amigos no más, y queríamos payar mejor. Y, sobre todo, el celo del Pedro, porque era muy exigente; y el conocimiento y la inteligencia del Santos Rubio que traía todo un historial como payador campesino. Así que estuvimos... no fueron muchos años, unos dos o tres 
años, pero aprendimos. Entonces le dimos una puesta en escena a lo que hacíamos.

M. G.: Eso fue idea suya, que tuviera partes el encuentro.

J. Y.: Seguramente. Todos los conocimientos de ritmo que yo tenía en el teatro, y esto del desenlace y de crear puesta en escena, indudablemente que yo hice mi aporte, aparte de aprender a payar.

M. G.: ¿Qué tenía que tener esta puesta en escena de la paya para que funcione?

J. Y.: Yo creo que un orden y un ritmo no más. Porque lo primero que hacíamos eran coplas populares que uno sabía, relances. Y después, ¿con qué podíamos seguir? Brindis, y ya, brindábamos. Después la décima. Pero lo que yo recuerdo con más cariño era la décima a dos razones, porque se juntaban dos pensamientos; entonces uno decía dos líneas y el otro trataba de seguirlas de acuerdo a ese planteamiento que decía el primero. Y eso resultaba muy encachao porque terminaba siempre en sorpresa.

M. G.: Ahi se subian de a dos.

J. Y.: Ahí nos dividíamos, el que tenía más experiencia podía payar con otro, pero era de a dos. Y después venía el contrapunto entre los dos que más dominaban la décima, que eran en este caso el Santos Rubio y el Pedro Yáñez. Y después veníamos el resto, el Alfonso, yo, el Piojo. Y así fuimos creando el espectáculo, de repente apareció la pregunta y respuesta al estilo de los payadores antiguos.

M. G.: Claro, Desiderio Lizana habla de eso.

J. Y.: Claro, don Javier de la Rosa y el payador, el mulato Taguada, ellos payaron en cuarteta, y esa era muy conocida. Entonces resultaba muy eficaz porque era pregunta y respuesta y era lo que más le gustaba al público, así que no podía faltar el contrapunto en cuarteta.

M. G.: Todavía, yo creo.

J. Y.: Es que sabes tú que el pueblo, la gente, tiene muy pegada la cuarteta, es casi natural en ella. Entonces cuando uno hace una cuarteta inicial para una décima la gente aplaude, no sabe que sigue, entonces hay que seguirle la línea de los diez versos a los payadores, que algunas veces salen muy bien y otras veces no salen tan bien. Y después de eso, cuando salíamos a los escenarios, como cada uno venía de un mundo artístico distinto -el Pedro dentro de lo tradicional y académico; el Santos Rubio eran sus conocimientos del campo, famoso, no se le iba ni una; y el Alfonso que era su hermano que lo seguía muy bien; el Piojo que improvisaba sobre cualquier cosa y yo también sobre 
cualquier cosa- aprendimos a payar en décima. Entonces ahí, después de estos contrapuntos, y de ir armando, teníamos que llegar al escenario. ¿Qué decidimos nosotros? Porque cada uno venía de un mundo distinto: yo venía del mundo del teatro, el Piojo venía de lo popular y tradicional de andar payando en cuarteta, Santos Rubio era campesino de tradición, y el estudioso y el más intelectual era el Pedro, que se hacía llamar a sí mismo "el pensador". Entonces, antes de iniciar el encuentro de payadores -el espectáculo nuestro-cada uno hacía un número distinto: el Piojo cantaba alguna canción equis, el Pedro hacía sus versos, el Santos Rubio hacía sus tonadas y yo hacía los versos que me había aprendido de cualquier poeta. Y una vez que nos presentábamos los cuatro, recién venía la paya, recién invitábamos a la gente a escuchar y les decíamos lo que íbamos a hacer: ahora vamos a payar de tal manera, se trata de esto, bla, bla, bla. Y ahí recién empezamos como a hacer clases para que la gente entendiera. No a hacer clases, sino que a enseñarles. Y el público siempre aceptó esta manera, este espectáculo de los payadores. Y terminaba, por supuesto, con un verso de despedida o cualquier tema. Y después se le empezó a pedir el tema a la gente, mucho después, todo lo hacíamos nosotros.

M. G.: ¿Pie forzado no hacían, entonces?

J. Y.: También, pero lo hacíamos nosotros, o sea: "vamos a payar un pie forzado, vamos a terminar en un verso octosílabo cualquiera: 'voy a agarrar la guitarra'. Ya, listo. ¿Con quién? Los dos. Ya, los dos”. Ahí teníamos que terminar. Entonces a la gente le decíamos: "vamos a payar, pero vamos a terminar "voy a agarrar la guitarra"”, por decir. Y así fuimos mezclando el espectáculo con la enseñanza del público. Y estuvimos harto tiempo, como dos o tres años haciendo ese trabajo.

M. G.: ¿Por qué la gente enganchó con los payadores? ¿Qué fue lo atractivo, finalmente?

J. Y.: Yo creo que a la gente le gusta la improvisación, le gustan los payadores. Pero, fundamentalmente, el público cree que se va a divertir, lo que le gusta es la diversión, cuando se atacan unos a otros, cuando pelean, se trenzan en el escenario, eso le gusta a la gente, y eso lo hace atractivo a la gente, que no debe, según yo, no debe perderse nunca. Porque el espectáculo está dirigido. Porque uno puede payar entre nosotros y ejercitarse, pero llevarle la paya al público es un poco más difícil. Pero nos dábamos cuenta de que a la gente le gusta reírse, piensa que los payadores son para la risa, nosotros tratábamos de sacarle esa idea de la mente, poníamos temas difíciles. Y así se nos pasó la vida.

M. G.: ¿Recuerda cuando apareció la concesión, por ejemplo? 
J. Y.: Fue otro señor, el Puma de Teno. Nosotros le llamábamos "hasta agotar la rima". Pero él dijo "no, eso se llama la concesión", porque nosotros ponemos un tema y ponemos un solo pie forzado interminable, todas las rimas que podamos encontrar en relación a ese pie forzado. Eso se llama concesión, nos dijo el Puma de Teno. ¿Tú ubicas Teno?

M. G.: Nunca he estado en Teno.

J. Y.: Es un pueblo antes de llegar a Curicó. Allá también se hicieron grandes encuentros de payadores.

M. G.: Y hasta más o menos poco, hace algunos años.

J. Y.: Y lo otro que tuvo una gran importancia fue que a un señor del diario La Tercera le interesó este mundo de la paya y decidieron apoyar en el diario a los payadores. Y empezamos a aparecer nosotros en los contrapuntos en el diario, fue un gran apoyo que hizo La Tercera. Y con La Tercera se prepararon los grandes encuentros de payadores en el Teatro Caupolicán, deben haber llegado unos veinte, treinta payadores de todo Chile, auspiciados por el diario La Tercera. Y nosotros, envalentonados por esto y agradeciendo la publicidad y el apoyo del diario, pensamos que podíamos ir a otros diarios. Fuimos a Las Últimas Noticias que también hiciera lo mismo, pero La Tercera quería tener la exclusividad y cortó el apoyo. Pero ya se habían desarrollado estos encuentros en el Caupolicán que fueron muy programados, muy publicitados, toda la gente fue, no te digo que lo llenáramos, pero por lo menos había medio teatro donde hay tres mil o cuatro mil personas.

M. G.: Hoy en día ya quisiéramos un encuentro así, con tanta gente.

J. Y.: Nosotros lo organizábamos en la Críspulo Gándara, hicimos diplomas para todos los payadores, primero, segundo y tercer lugar, etcétera.

M. G.: ¿Era competitivo, entonces, esto?

J. Y.: Totalmente competitivo. Un señor que se creía el rey de los payadores... se consideraba el mejor payador de Chile. Y fue, se presentó ante nosotros para payar contra cualquiera. Entonces nosotros los ordenábamos al azar a todos estos viejos y payó con alguien que no salió muy bien parado este payador de Curicó. Y cuando viene la entrega de los premios (primero, segundo, tercer y cuarto lugar, y las promesas de la paya y todo lo demás) este señor salió como décimo. Y cuando le entregamos el diploma en el escenario del Teatro Caupolicán, lo bota. "Esto no es mío", dice.

M. G.: ¿Y usted participó?

J. Y.: Sí, nosotros participábamos, si nosotros organizábamos esos encuentros con el diario La Tercera y participábamos todos. 
M. G.: ¿Se acuerda de algún payador destacado en esos encuentros que haya estado dentro de los primeros lugares?

J. Y.: Es que yo creo que por la misma popularidad que nosotros teníamos y por el hecho de estar organizando y estar payando todo el tiempo con el público, la mayoría de los premios recaían en nosotros. Ganaba el Pedro, o ganaba el Santos o ganaba el Piojo o ganaba yo o sacaba el tercer, cuarto lugar, no importaba.

M. G.: ¿Y qué es lo que tenían ustedes que no tenían los otros, que siempre ganaran?

J. Y.: No tenían el talento, de partida, no tenían la práctica, andaban payando solos por ahí con otros viejos que a lo mejor no eran tan exigentes. Pero acá fue un taller muy positivo para aprender a payar, y el uso del escenario, y además divertirnos. Nosotros nos divertíamos mucho. Hasta el día de hoy los payadores se matan de la risa. Bueno, nosotros también nos matábamos de la risa con las tonteras que hacíamos. En el fondo era un entretenimiento y era una manera de ganarnos la vida también, porque en esos tiempos no había mucho trabajo. Entonces, empezamos a cobrar por nuestro espectáculo.

M. G.: ¿Cuánto duraban estos encuentros?

J. Y.: Unas dos horas. Nosotros le pusimos así con todos estos espacios.

M. G.: ¿Practicaban entre ustedes cuando no estaban en el escenario? J. Y.: Claro.

M. G.: ¿Y tenían un horario en la semana?

J. Y.: Nos juntábamos dos o tres veces en la semana en la casa de un amigo, del "Gordo" San Martín, que era como el representante de la Críspulo Gándara, ese andaba vendiendo el espectáculo por ahí, en alguna parte. Y le salía bien. Recorrimos, fuimos al sur varias veces, en Santiago varias veces, y de repente se presentó la oportunidad de actuar en el Teatro Ópera en el centro de Santiago, donde estaba el Bim Bam Bum.

M. G.: ¿Dónde era eso?

J. Y.: En Huérfanos, entre Estado y San Antonio. Era muy popular ese teatro, el Bim Bam Bum. Y ahí llegamos los payadores, y estuvimos como un mes payando todos los días.

M. G.: Era como una temporada de payadores.

J. Y.: Una temporada, claro. Y ahí, te digo (ríe) lo pasábamos muy bien porque ya se crearon las duplas, entonces ya el Pedro no payaba solamente con el Santos, sino que conmigo o con el Piojo Salinas, y el Santos Rubio con 
el Piojo, y así nos turnábamos. Pero la dupla más poderosa era el Pedro con Santos Rubio, después venía el Piojo conmigo. Y lo pasábamos muy bien.

M. G.: ¿Ustedes se hacian acompañar siempre tocando, o de repente era de apunte?

J. Y.: Todos tocábamos nuestras guitarras, supiéramos o no supiéramos.

M. G.: Como saliera.

J. Y.: Claro. Ahora, yo tocaba la guitarra y, para payar, yo me aprendí muchas melodías con el Santos Rubio.

M. G.: Se aprendió melodías a lo poeta.

J. Y.: Sí.

M. G.: ¿Y Santos tocaba el guitarrón?

J. Y.: Sí. Tocaba el arpa, tocaba el acordeón, lo que a él se le ocurriera, esos instrumentos él dominaba. El Pedro, que tiene una guitarra maravillosa, y el Piojo Salinas, que charrangueaba bien su guitarra también. Ahora, si tocaba el caso de que hiciéramos duplas, entonces ahí tocaba uno... por el tono. Si íbamos a payar junto con el Santos Rubio, Santos me decía: "en sol, Jorge", así que payábamos con la misma melodía. Se pasó muy bien.

M. G.: ¿Y ocupaban la común, u ocupaban algunas otras igual?

J. Y.: Yo no les sé el nombre a las melodías. Yo te conozco varias melodías pero no tengo memoria como para decir: "Esta es la puntillana, esta es la común”. La más famosa era la rosa romero y el alelí. ¿Cómo se llama esa?

M. G.: Así se llama, la rosa romero.

J. Y.: La rosa romero era la más común. Yo nunca me aprendí los nombres, sino que los seguía no más y, además, si me tocaba a mí, yo inventaba cualquiera de las que me sabía.

M. G.: O sea, igual manejaba un pequeño repertorio.

J. Y.: Todos nosotros lo mismo.

M. G.: ¿Tenían también condiciones para cantar?

J. Y.: El Pedro, que canta muy bien, el Santos Rubio con su cantar campesino, el Piojo Salinas ya venía la vida cantando, y yo aprendí a cantar con ellos y con otras personas y además como hacía mi trabajo individual... Todos cantábamos.

M. G.: Y de este grupo, ¿quién se destacaba por manejar el público, o que el público quisiera más?

J. Y.: Era muy equiparado. Dependía del ingenio del payador, dependía de su remate. El Pedro era un excelente guitarrista, pero también de repente no 
le encontraba el remate apropiado. Entonces, lo encontraba Santos Rubio. No había ninguno de nosotros que destacara más allá de nuestras posibilidades, de nuestra simpatía, de nuestro conocimiento. Para el público éramos los cuatro. En el fondo, cada uno demostraba sus condiciones artísticas, su simpatía, su talento. Además, yo era muy conocido a través de la televisión, entonces la gente me miraba con mucho respeto, a mis compañeros igual.

M. G.: En ese momento, ¿qué trabajos suyos se habían visto en televisión?

J. Y.: Muchas, porque yo empecé en el año 62. Y en el año 72 yo hice de Manuel Rodríguez en la televisión. Yo era Manuel Rodríguez, entonces eso también apoyaba mucho -después del golpe- lo que andábamos haciendo. Fue después del golpe cuando nos juntamos entre todos, pero antes cada uno andaba por su cuenta.

M.G.: Hoy en día mucha gente tiene un concepto errado-ahora que nombró el golpe y la dictadura en general-, un concepto de payador como una persona que dice versos hechos, que charranguea un poco la guitarra y que recita. Cuando dicen "un payador" no mucha gente se imagina a un señor que toca a lo poeta, que improvisa en décimas, que pide temas. ¿Qué cree que pasó que la gente empezó a creer que el payador era un campesino que charrangueaba la guitarra y que recitaba versos?

J.Y.: Eso es la memoria del pueblo, eso es lo que la gente cree que es un payador, y eso es bien difícil sacárselo de la cabeza. Porque hay una cultura que la gente tiene que, aunque no haya visto nunca a un payador, sabe que los payadores son graciosos. ¿Por qué? Porque el mismo encuentro entre don Javier de la Rosa y el Mulato Taguada está lleno de ingenio y de simpatía; entonces, la gente se acostumbró a eso. Y además hay un detalle negativo en todo esto, porque nosotros llegamos a la televisión casi al final de la dictadura. En la televisión salió un "payador" que ganó un concurso, pero no payaba, sino que rimaba. Eso para la gente era un payador, y fue muy famoso, y creo que hasta el día de hoy anda cantando por ahí gracias a ese programa de televisión y gracias a esas rimas, que para la gente eso es payar. Pero era solo, cantaba solo; para nosotros payar siempre fue un juego como debe ser, un contrapunto entre dos, tres o más poetas, hay una rueda de poetas populares que improvisan. Y ese señor se llamaba Lalo Vilches.

M.G.: ¿Usted lo conoció?

J.Y.: Sí, pues, si todavía lo conozco.

M.G.: ¿Y por qué a él se lo presentó como payador? ¿A él mismo se le ocurrió o algún productor de televisión dijo "pongamos que es payador"? 
J.Y: No, él se decía payador, igual que ese otro viejo que botó el diploma allá en el Teatro Caupolicán años atrás. Lo que pasa es que él... había un concurso famoso, no sé cómo se llama... Entonces iban los artistas a postular a ese concurso, cuál de todos tenía una gracia distinta: un tony, un cantante, un mimo, un bailarín, y apareció un payador. ¿Y qué es lo que le llamó la atención a la gente? Que este señor rimaba muy rápido; entonces, eso les llamó la atención a los productores y lo metieron al programa. Entonces, él apareció en la televisión chilena payando así: "Aquí estoy, señorita / como la veo yo / tiene que tener cuidado / no le roben el reloj / no le roben el reloj / porque aquí yo estoy parado / porque estoy payando / y usted está entusiasmado / y usted está entusiasmado..." Y eso le encantó a la gente; y nosotros no sabíamos qué hacer, cómo llegar a la televisión para decirle que eso no era payar. Después, cuando lo conocimos personalmente $-\mathrm{y}$ en la entrevista que alguna vez se nos hizo nos ponían de ejemplo a este caballero- decíamos nosotros que eso no era un payador. Porque él era un cantor popular que rimaba, no era paya lo que él hacía. Pero para la gente eso era la paya desgraciadamente. A mí me dicen: "Don Jorge, tírese una paya". Y yo estando en la televisión improvisé mucho en verso y los hice especialmente para algunos programas, entonces me anunciaban como un payador. Y yo le decía al director: "Sabe que yo no soy un payador, yo vengo aquí como poeta popular, como improvisador". "Ya, pero te presentamos como payador, eso vende". Y así era. Esa es la mentalidad de la mayoría de la gente del pueblo, encontrar al payador que dice versos graciosos y a todo le llama paya. Va a costar mucho sacarse esa idea.

M.G.: ¿Y en qué momento empezaron a juntarse los payadores de acá, usted mismo incluido, con los extranjeros?

J.Y.: Por ejemplo, una idea casi nueva, una iniciativa del Santos, del Pedro ya de invitar a los... Ya no existió la Críspulo Gándara, nos fuimos cada uno por su lado. Entonces, ellos encontraron que -al ir creciendo del verso, de la paya, ahora en décimas- los taitas de esto son de Argentina para allá, Uruguay, Brasil, Venezuela, México, Cuba. Esos viejos han payado siempre en décima, siempre. Nosotros estamos atrasados en ese sentido; en décima se empezaría a payar en los años ochenta para adelante. Pero ellos, desde principios del siglo pasado. Los argentinos, por ejemplo, tienen una película que se llama El último payador, y trata de un payador que anda por los caminos de Dios. Entonces, la cultura de ellos es muy fuerte, y en décimas. Entonces, yo creo que al Pedro y a otras personas se les ocurrió esto de invitar a los extranjeros para poder medirse con ellos, una manera de desarrollarse y de crecer. 
M.G.: ¿A usted le tocó enfrentarse payando con alguno de ellos?

J.Y.: No, nunca. No, yo ya estaba lejos de ellos, ya después me fui alejando. Si me invitan a payar y yo tengo ganas lo hago; si no, no. Yo no vivo como payador, a mí me gusta la poesía, a mí me gusta payar, pero tengo que estar como en familia. Ahora, yo he ido a muchos encuentros después, y fui al primer encuentro que se hizo en Casablanca, eran puros chilenos.

M.G.: ¿Pero usted estuvo presente, por ejemplo, en alguno de esos encuentros cuando vinieron los argentinos?

J.Y.: No. Yo fui después, cuando supe que venían extranjeros fui de visita a ver cómo era este asunto. Y la verdad es que no me gustó para nada.

M.G.: ¿Qué cosa?

J.Y.: El encuentro con los payadores extranjeros.

M.G.: ¿Qué fue lo que ocurrió?

J.Y.: Lo que pasa es que nosotros, con nuestras melodías ancestrales, nuestra manera de payar, es una cultura que tiene visos de espectáculo. Y algunos lo ven así y le dan en el gusto al público sobre cualquier cosa para que se ría, pero la guitarra y el guitarrón están presentes en la paya nuestra. Pero aparecieron estos payadores extranjeros y son verdaderas orquestas. Cuando yo veo payar a los cubanos, que son excelentes, extraordinarios, pero payan con su son.

M.G.: Y ellos tienen, por lo menos, dos músicos que los acompañan.

J.Y.: Claro, y los venezolanos igual, y los peruanos igual, y payan con sus ritmos populares que ellos tienen, y los colombianos igual, métale cumbia... O sea, son espectáculos musicales en donde se usa el verso, se usa la paya, pero con una fuerza y una llegada totalmente superior al espectáculo chileno.

M.G.: Se sintieron menoscabados, entonces, ¿o no?

J.Y.: No, yo... no me gustó, pero los payadores no le han dado mayor importancia.

M.G.: ¿No le gustó el contraste?

J.Y.: Claro, era mucha la diferencia entre la calidez y el canto a lo humano de un payador chileno, que es lánguido: (Canta usando la entonación común): "Yo me presento, señores: // con mi canto de improviso / esto no es el paraíso / más bien tierra de dolores."

M.G.: Claro, y eso no es muy animado.

J.Y.: Pero así es lo nuestro y uno se acostumbró a eso. Entonces, llegaron los payadores con su fuerza, sus ritmos, sus instrumentos, su colorido de 
presencia escénica, eso es show. Pero así lo hacen ellos en esos países, son show.

M.G.: Claro, he visto unos contrapuntos de cubanos, por ejemplo, en internet, y duran una hora, dos horas incluso en un contrapunto.

J.Y.: Claro, es que además el Bigote te lo puede haber dicho, el viajó a Cuba, y allá se dio cuenta de que hay una universidad donde tiene que aprender un payador. Entonces, además del talento que pueda tener un payador, hay una formación musical y poética que es una tradición que viene de años, años luz. Entonces, es difícil hacerles el peso a esos viejos. Se irá a llegar el día de mañana que el payador chileno tenga vuelo poético y domine muy bien el idioma, y domine muy bien la rima con sentido, domine bien la guitarra, cosa que realmente sea un exponente moderno de lo que es la paya, en relación a los extranjeros. Para nosotros está bien, pero para ellos...

M.G: Y en ese momento, cuando salían con la Críspulo, ¿se preocupaban, por ejemplo, de la ropa con la que iban a salir?

J.Y.: No.

M.G.: ¿Salían como anduvieran?

J.Y.: No, siempre con camisa limpia, bien planchado.

M.G: ¿Pero no había una...?

J.Y.: ¿Estética? No, no existía eso.

M.G.: Bueno, ahora no sé si la haya, no estoy seguro. Hoy en día, ¿en la paya existiría algo como la estética que represente a un payador?

J.Y.: No, hoy día con los cabros he estado hace poco no más en encuentros de payadores y los muchachos se visten como se visten, no más. Algunos se visten medio de huaso, otros de short o con sombrerito corto, de pañuelo al cuello... Tratan de darle cierta personalidad, cierta estética, pero son todos diversos porque el payador también es diverso: no todos tienen tanta personalidad, no todos son unos exuberantes, no todos son buenos en lo que hacen, hay de todo.

M.G.: O sea, estamos viendo que el payador en el futuro tiene que tener más vuelo poético, tiene que dominar el léxico, tiene que tocar y cantar bien.

J.Y.: Sí.

M.G.: ¿Hay algo más que tenga que tener un payador, aparte de todo eso?

J.Y.: (Ríe) No, tiene que ser talentoso, no más. El talento es lo único que lo salva. Por ejemplo, tenemos a un cabro, al Manuel Sánchez. Descubrió una manera de payar con cierto vuelo, y sale como de la casa al escenario, no se preocupa nada de su estética. ¿Qué es lo que le interesa a él? Su mente, 
su cabecita loca para improvisar frente a otro payador. Yo lo veo, es muy bueno lo que él hace. En cambio, hay otros que son tradicionales que no... Por ejemplo, un caballero, creo que es el hermano de la payadora...

\section{M.G.: Francisco Astorga.}

J.Y.: Ese, es un cura de la paya, ese no soporta nada. Y es buenísimo lo que hace, pero ese sí que está metido en la tradición, y hace buenos versos.

M.G.: Ahora, ¿usted en ningún caso cree que se esté pasando a llevar a la tradición con el espectáculo de payadores como se hace hoy día?

J.Y: No, porque cuando se habla de tradición son costumbres, y las costumbres van cambiando con el tiempo. Pero lo que no cambia -que a eso se aferra la tradición nuestra- es el talento para improvisar, eso tiene que ser cada vez más fuerte, más poderoso, más encantador, más inteligente, eso es lo que va creciendo. Entonces, da lo mismo cómo te vistas.

M.G.: Ya han pasado más o menos 38 años desde que surgió la Críspulo. ¿Se ha visto alguna mejora en esto de lo que usted está hablando, de la necesidad de mejorar?

J.Y.: Sí, yo lo he visto, sí, los muchachos de ahora... Una cosa que antes no se usaba y ahora es como obligación: que toquen el guitarrón. Andan todos con sus guitarrones, y eso da gusto. Eso sí que es un aporte y una tradición que se debe conservar. Aparte de tocar bien la guitarra hay que tocar bien el guitarrón, y el guitarrón tiene un sonido atávico, ancestral; ese sí que es tradicional, misterioso, encantador. Tú escuchas un guitarrón y te vas para Chile altiro, tiene identidad, que es muy importante.

M.G.: ¿Qué es lo que tendríamos que hacer los payadores para mejorar esta puesta en escena?

J.Y.: Estudiando todas las formas verbales que se puedan usar en la paya, tener como un diccionario clarísimo de la rima, en su cabeza, digo. Y ser inteligente en la coordinación de su propuesta y de su respuesta, eso es fundamental. ¿Por qué? Porque el léxico... No sé si tú ubicas muy bien al payador argentino o uruguayo, un diccionario de palabras que parece que nacieron con ellas.

\section{M.G.: Cuba también.}

J.Y: Por eso te digo, de México hasta la Argentina. Te nombré varios, los mexicanos, los colombianos, los cubanos, peruanos, los argentinos, los uruguayos, venezolanos, todos saben payar, todos son buenos, son buenísimos. Y aquí en Chile ha crecido mucho la paya, de lo cual me alegro, ha crecido mucho, y se ve que hay un avance en los jóvenes que están cuidando su rima, 
es muy importante. Además, están tocando guitarrón, que es muy importante. Sí, se ve un avance.

M.G.: ¿Podría mencionar algún exponente actual de la paya, que esté representando este afán de mejora o que ya esté más o menos consolidado, que tenga buen verso?

J.Y.: Bueno, hay varios. Manuel Sánchez es uno de ellos.

M.G.: ¿Ya no le dan ganas de ir a ver un encuentro de payadores?

J.Y.: No, porque yo estuve muchos años en eso de los payadores, hasta ahora último. Una de las cosas que me ha llamado la atención es los grupos que se han armado de payadores. El último grupo en que yo participé era Santos Rubio, Alfonso Rubio, el Bigote Villalobos y yo, los cuatro. También salimos a payar por los caminos, anduvimos por Temuco y todos los pueblos en sus alrededores, invitados por la [Universidad] Católica de esa región. Lo pasamos súper bien. Y grabábamos por donde íbamos, y en Panguipulli fue lo mejor que pudimos rescatar para sacar un disco, éramos Los Cuatro de la Rosa. Entonces, yo creo que uno de los grandes y buenos payadores es el Alfonso Rubio. Alfonso Rubio es súper inteligente, muy habilidoso, junto con este Manuel Sánchez. Leonel Sánchez también es bueno, el Bigote también. El Bigote lo que tiene es una mezcla entre lo que era el Piojo Salinas... una mezcla entre picardía e inteligencia.

\section{M.G.: Pedro era inteligente, según usted.}

J.Y.: Bueno, yo creo que al Pedro Yáñez habría que rendirle un monumento, porque ese es un maestro, uno de los grandes payadores chilenos, de los antiguos estoy hablando. En estos encuentros que he ido yo los encuentro muy simpáticos a todos, las mujeres también.

M.G.: ¿Por qué cree usted que hay tan pocas mujeres en la paya?

J.Y.: No es porque seamos machistas, pero hay un problema que yo encuentro con la mujer. La cultura nuestra, como chilenos o como latinoamericanos, hace que seamos muy respetuosos con la mujer. Entonces, nos cuesta mucho faltarle el respeto a una mujer, agarrarla para el fideo. La mujer lleva todas las de ganar en un encuentro de payadores.

M.G.: En ese sentido, el hombre quedaría en desventaja.

J.Y.: Eso, para nuestro orgullo varonil, no es bueno. Porque nosotros somos un país criado así, a la manera de nosotros, los hombres. Cuesta mucho darle esa misma tribuna a una mujer. Ahora, también pueden las mujeres andar entre ellas payando, sería ideal. 
M.G.: De hecho, el 6 de octubre va a haber un encuentro solo de mujeres en Valparaíso.

J.Y.: Yo creo que van a llegar a eso las mujeres, a payar entre ellas, porque ahí sí que hay libertad de tratarse de una manera abierta, franca, directa, aunque se hieran.

M.G.: Parece que es clave un tema de sentirse en confianza para poder decirle cosas al otro.

J.Y.: Nosotros, justamente, éramos un grupo que lo pasaba muy bien, éramos todos amigos, hasta el día de hoy seguimos siendo amigos todos y nos respetamos, nos queremos y nos defendemos.

M.G.: Ahora, como para ir cerrando. ¿Qué relación hay, o qué tiene de teatro, la paya?

J.Y.: Desde el momento en que... Hijo, por eso te digo. Antiguamente los poetas populares iban a las fiestas religiosas; por lo tanto, hay un motivo para juntarse. Todos tienen un objetivo al cantar: le van a cantar al niño Dios que acaba de nacer, otros le van a cantar a la natividad de la Virgen María. Entonces, hay un objetivo común. Después de que se cumple esa misión, se liberan y empiezan a payar sobre temas mundanos, pero siempre entre ellos. Pero cuando la paya sale a los escenarios comercialmente hablando, porque ahora todos los payadores se hacen pagar...

M.G.: Claro, ahora cobran por la entrada o por sus servicios.

J.Y.: Nosotros inventamos eso, empezamos a cobrar, porque es un espectáculo. Y desde el momento en que tú te subes a un escenario ya estás actuando.

M.G.: O sea, hay una diferencia entre el payador abajo del escenario y arriba del escenario.

J.Y.: Claro.

M.G.: ¿Y qué hace esta diferencia?

J.Y.: Enfrentar a un público, actuar. Hay algunos que no le dan importancia a eso, pero desde el momento en que nosotros nos presentamos ante un público adquirimos otra personalidad, que es la del artista y creador, y un señor que lucha por que se le escuche.

\section{BIBLIOGRAFÍA}

YÁÑEZ, JoRGE. Entrevista oral. 28 de septiembre de 2018. 